\title{
Genome-wide association mapping for type and mammary health traits in French dairy goats identifies a pleiotropic region on chromosome 19 in the Saanen breed
}

\author{
Pauline Martin, ${ }^{*}$ Isabelle Palhière, ${ }^{*}$ Cyrielle Maroteau, ${ }^{*}$ Virginie Clément, $†$ Ingrid David, ${ }^{*}$ \\ Gwenola Tosser Klopp, ${ }^{*}$ and Rachel Rupp*1 \\ *GenPhySE, Université de Toulouse, INRA, ENVT, Castanet Tolosan, F-31326 France \\ †'nstitut de l'Elevage, Chemin de Borde Rouge, Castanet Tolosan, F-31326 France
}

\begin{abstract}
Type traits and mammary health traits are important to dairy ruminant breeding because they influence animal health, milking ability, and longevity, as well as the economic sustainability of farms. The availability of the genomic sequence and a single nucleotide polymorphism chip in goats has opened up new fields of investigation to better understand the genes and mechanisms that underlie such complex traits and to be able to select them. Our objective was to perform a genome-wide association study in dairy goats for 11 type traits and somatic cell count (SCC) as proxies for mastitis resistance. A genome-wide association study was implemented using a daughter design composed of 1,941 Alpine and Saanen goats sired by 20 artificial insemination bucks, genotyped with the Illumina GoatSNP50 BeadChip (Illumina Inc., San Diego, CA). This association study was based on both linkage analyses and linkage disequilibrium using QTLmap software (http://dga7.jouy.inra.fr/qtlmap/) interval mapping was performed with the likelihood ratio test using linear regressions. Breeds were analyzed together and separately. The study highlighted 37 chromosome-wide significant quantitative trait loci (QTL) with linkage analyses and 222 genome-wide significant QTL for linkage disequilibrium, for type and SCC traits in dairy goats. Genomic control of those traits was mostly polygenic and breed-specific, suggesting that within-breed selection would be favored for those traits. Of note, Capra hircus autosome (CHI) 19 appeared to be highly enriched in single nucleotide polymorphisms associated with type and SCC, with 2 highly significant regions in the Saanen breed. One region $(33-42 \mathrm{Mb})$ was significantly associated with SCC and includes candidate genes associated with response to intramammary infec-
\end{abstract}

Received August 3, 2017.

Accepted January 26, 2018.

${ }^{1}$ Corresponding author: rachel.rupp@inra.fr tions (RARA, STAT3, STAT5A, and STAT5B). Another region of the CHI 19 (24.5-27 Mb) exhibited an adverse pleiotropic effect on milk production (milk, fat yield, and protein yield) and udder traits (udder floor position and rear udder attachment) that agreed with the negative genetic correlations that exist between those 2 groups of traits. These QTL were not found in the Alpine breed. In Alpine, the 2 most significant regions were associated with chest depth on CHI 6 (45.8-46.0 $\mathrm{Mb})$ and $\mathrm{CHI} 8(80.7-81.1 \mathrm{Mb})$. These results will be helpful for goat selection in the future and could lead to identification of causal mutations.

Key words: type traits, udder, mastitis, somatic cell count, goat, genome-wide association study (GWAS)

\section{INTRODUCTION}

As dairy goat farming mainly targets cheese production, goat-breeding programs tend to focus on milk production and composition. However, during the last decade, other functional traits in this species have been investigated and their genetic variability documented. Udder morphology is associated with milking ability and machine milking ease (Marnet and McKusick, 2001) and it affects duration of animal productive life by reducing premature culling due to morphological defects (Clément et al., 2006). Eleven heritable morphological traits (Manfredi et al., 2001) are routinely recorded in French primiparous goats. Furthermore, a genetic opposition with production has been documented in French populations (Manfredi et al., 2001), which provides evidence that the highly successful selection for milk production has likely led to a deterioration in udder shape. Five udder type traits, which explain $80 \%$ of the genetic variability of udder and teat morphology (Clément et al., 2006), were therefore included in the French selection index in 2006: udder profile, udder floor position, fore udder, rear udder attachment, and teat orientation. Since 2013, milk SCC has also been selected against as a means of reducing subclinical mas- 
titis. Milk SCC ( $\mathrm{h}^{2}=0.2$ in goats) has been used widely in dairy ruminants as an indirect predictor of udder health status (Rupp and Foucras, 2010; Rupp et al., 2011) and is recorded routinely in French dairy goats. Somatic cell count can be recorded at low marginal cost during routine milk recording, whereas clinical mastitis diagnosis is more expensive. As a constant increase in the level of SCC has been observed on French goat farms in recent decades (Clément et al., 2016), this trait has been introduced to improve both animal health and milk quality. In the current breeding objective, udder morphology accounts for $28 \%$ and SCC for $17 \%$ in Saanen goats, and $25 \%$ and $13 \%$ respectively, for Alpine goats (Palhière et al., 2015).

The availability of the genomic sequence in goats (Dong et al., 2013) has opened up new fields of investigation to better understand and select for traits of interest in this species. The development of a high-density SNP array (Tosser-Klopp et al., 2014) and its application in genome-wide association studies has facilitated the identification of regions that control caprine traits such as polledness (Kijas et al., 2013), wattle (Reber et al., 2015), coat color (Martin et al., 2016b), supernumerary teats (Martin et al., 2016a), and milk production (Martin et al., 2017). However, very little is known about the loci controlling type traits and lactation SCS (LSCS) in this species. To our knowledge, only one study on QTL detection of caprine body conformation traits was published (Marrube et al., 2007), based on a low-density panel of microsatellites in Angora goats.

In this paper, we report a genome scan for 12 type and health traits, including udder type traits, SCC, and stature in Saanen and Alpine dairy breeds. We performed linkage analyses (LA) and linkage disequilibrium (LD) analyses in a large family design of 2,209 goats, based on Illumina GoatSNP50 BeadChip (Illumina Inc., San Diego, CA) data to identify genomic regions responsible for type and health traits and to nominate potential candidate genes.

\section{MATERIALS AND METHODS}

\section{Ethics Statement}

The DNA samples for this study came from France and are stored at the Laboratoire d'Analyses Génétiques pour les Espèces Animales, Jouy-en-Josas, France (LABOGENA; www.labogena.fr). Sperm was collected from bucks by Capgenes, with authorization from the Direction Générale de l'Alimentation; FR CC 860), and we used extra doses from this collection. Blood samples were taken at commercial farms. The animals were not part of any experimental design but were sampled by veterinarians or under veterinarian supervision for routine veterinary care; extra samples were requested when blood sampling took place.

\section{Animals}

The data came from 2,209 French dairy goats sampled in 2010 as part of the national "Genomcap" and the European Union "3SR" (www.3srbreeding.eu) projects described previously in Martin et al. (2017). The 2,209 animals were distributed in 20 half-sib families sired by 9 Saanen and 11 Alpine AI bucks. Family size averaged $109( \pm 16)$ daughters per buck and ranged from to 73 to 126 .

\section{Genome-Wide SNP Genotyping and Quality Control}

All 2,209 animals were genotyped using the Illumina GoatSNP50 BeadChip (53,347 SNP); DNA was extracted from blood samples and genotyping was performed at LABOGENA (www.labogena.fr). Data were cleaned using an in-house pipeline as described by Martin et al. (2017). In brief, any individual with a call rate below $95 \%(\mathrm{n}=16)$ or showing pedigree inconsistency ( $\mathrm{n}=228$; i.e., $10 \%$ ) was discarded. Quality control of SNP included the following inclusion criteria: call rate $>99 \%$, minor allele frequency $>1 \%$, and Hardy-Weinberg $P$-value $>10^{-6}$. After edits, a total of 47,174 out of 53,347 synthesized SNP remained, and a total of 44,612 SNP distributed on goat (Capra hircus, CHI) autosomes CHI 1 to CHI 29 were included for further analyses. The marker order and positions were based on the caprine Assembly CHIR_1.0 downloaded (December 9, 2014) from the following link: http:// bioinformatics.tecnoparco.org/SNPchimp/index.php/ download/download-goat-data.

\section{Phenotypic Measurements}

The following 11 type traits were considered: fore udder (FU), udder profile (UP), udder floor position (UFP), rear udder (RU), rear udder attachment (RUA), teat length (TL), teat form (TF), teat angle (TA), teat orientation (TO), chest depth (CD), and foot orientation (FO). The definition of the traits is as used in Manfredi et al. (2001) and Rupp et al. (2011). Teat length and CD were directly measured on the animal; the other type traits were given appraisal scores ranging from 1 to 9 . All type traits were recorded once, during the first or (occasionally) second lactation ( $1 \%$ in genotyped animals) using official classifiers from the breeders' association Capgènes (Mignaloux Beauvoir, France). The LSCS was computed from the monthly 
Table 1. Descriptive statistics for raw data for 11 type traits and lactation SCS (LSCS) traits in 1,941 genotyped dairy goats $($ Alpine, $\mathrm{n}=787$; Saanen, $\mathrm{n}=1,154)$

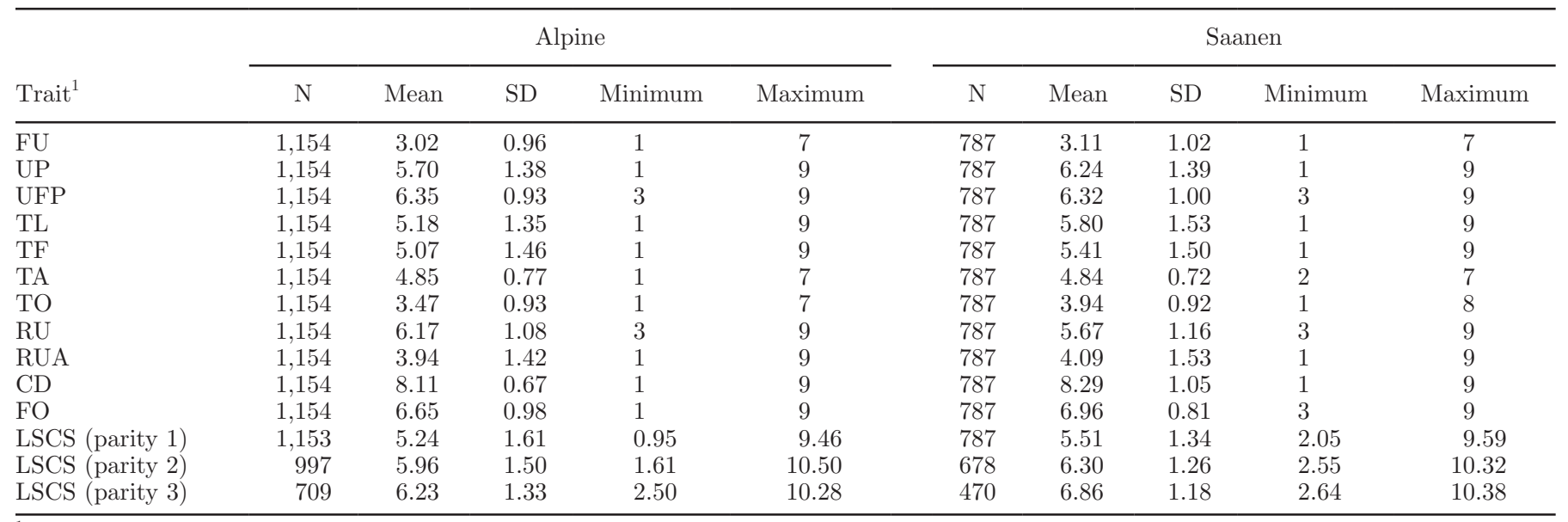

${ }^{1} \mathrm{FU}=$ fore udder; $\mathrm{UP}=$ udder profile; $\mathrm{UFP}=$ udder floor position; $\mathrm{TL}=$ teat length; $\mathrm{TF}=$ teat form; $\mathrm{TA}=$ teat angle; $\mathrm{TO}=$ teat orientation; $\mathrm{RU}=$ rear udder; RUA = rear udder attachment; $\mathrm{CD}=$ chest depth; and $\mathrm{FO}=$ foot orientation. Type traits were scored mainly in first lactation $(\mathrm{n}=1,141$ in Saanen; $\mathrm{n}=782$ in Alpine) or in second lactation ( $\mathrm{n}=13$ in Saanen; $\mathrm{n}=5$ in Alpine) in the genotyped data set.

test-day SCC as described by Rupp et al. (2011). Briefly, the test-day SCC were transformed to SCS by logarithmic transformation (Ali and Shook, 1980) to achieve a normal distribution. The LSCS was then computed as the weighted arithmetic mean of the testday SCS adjusted for DIM. Description statistics for raw phenotypes for genotyped animals are presented in Table 1.

For genome-wide association testing, yield deviations for all traits were used as provided by the official French national genetic evaluation (Clément et al., 2002). Yield deviations were raw data corrected for the effects included in the genetic evaluation models. For type traits, the fixed effects were age and lactation stage at the scoring date, and flock by year and parity combination, with number of levels equal to 13 (15), 17 (21), and 108 (131), for Saanen (Alpine) animals in the data set $(n=1,941)$, respectively. For LSCS, the raw data were corrected for the fixed effects of flock, age at kidding, month of kidding, dry period length (by parity, year, and region combination), and the random permanent environment. The number of levels were equal to 393 (449), 81 (96), 75 (91), and 56 (64) for Saanen (Alpine) animals in the data set $(\mathrm{n}=1,941)$, respectively. The yield deviations for each lactation (only the first 3 lactations were considered) were averaged by animal. A total of 1,941 phenotyped and genotyped animals were used for QTL mapping.

\section{Statistical Analyses}

Population Stratification. A principal components analysis (PCA) based on SNP information was conducted on the genotypes of the 1,941 genotyped animals using PLINK (v1.90b3.32; Purcell et al., 2007) to construct and plot the population structure. As illustrated in Figure 1, the population structure reflected the 20 families distributed in 2 breeds in our daughter design. Consequently, linkage and association mapping were conducted separately by breed and combined in a joint analysis, taking into account the family structure in the models.

Linkage and Association Mapping. The QTL associated with the 11 type traits and LSCS were mapped separately by breed and also combined in a joint analysis. Both LA and LD using interval mapping were applied using the QTLMap software (Elsen et al., 1999; http://dga7.jouy.inra.fr/qtlmap/). For LA, interval mapping (Lander and Botstein, 1989) was performed with the likelihood ratio test (LRT) using within-sire linear regression (Knott et al., 1996). The QTL effect (average substitution effect) was expressed in phenotypic deviation units (standard deviation, SD) for the trait. Linkage disequilibrium was based on a regression analysis of the phenotypes against the founder haplotypes (Legarra and Fernando, 2009). Both LA and LD analyses provided a test for each genomic position (here, every $0.1 \mathrm{Mb}$; i.e., 24,015 tests over the genome) using the surrounding SNP information.

Chromosome-wide significance levels were calculated with QTLMap, using the current family structure and the milk yield trait from Martin et al. (2017). For LA, the empirical 5 and $1 \%$ chromosome-wide significance levels of the test statistics were estimated from 1,000 within-family permutations (Churchill and Doerge, 1994) for each chromosome. For LD, the empirical 


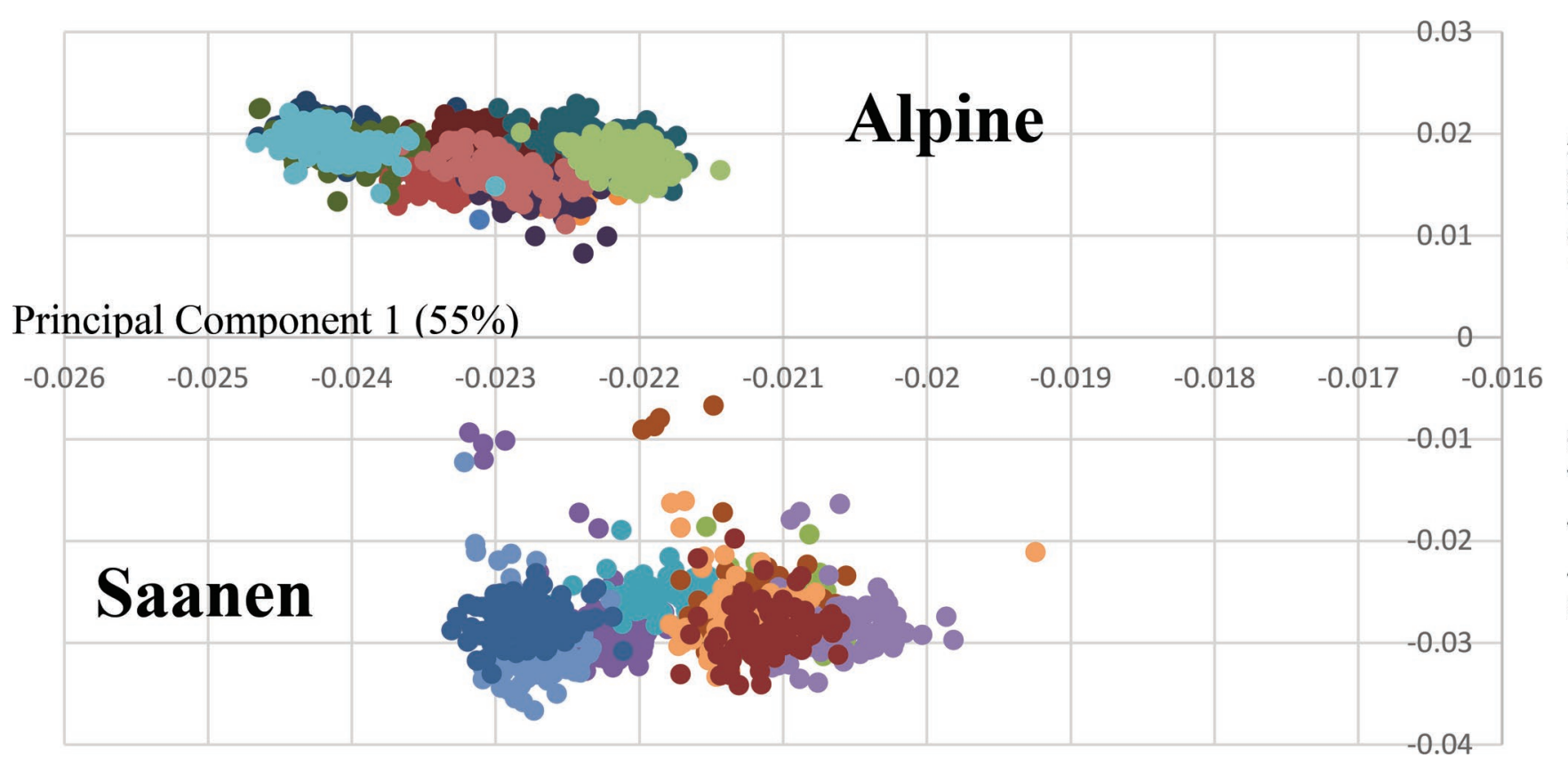

Figure 1. Population structure map drawn from the first 2 principal components (PC1 and PC2) of a principal component analysis based on 44,250 SNP from 1,941 animals distributed in 20 half-sib families sired by 9 Saanen and 11 Alpine bucks. The first 2 components explain 55 and $8 \%$ of variance, respectively. Color version available online.

chromosome-wide significance level of the test statistics was estimated from 1,000 simulations for each chromosome, assuming a heritability of 0.35 for the trait. The $5 \%$ genome-wide thresholds were obtained by applying the Bonferroni correction $P_{\text {genome-wise }}=1-(1-$ $\left.P_{\text {chromosome-wise }}\right)^{n}$, where $n$ was the number of autosomes analyzed (i.e., 29). The 95\% CI of the QTL locations were estimated with the logarithm of odds drop-off (Lander and Botstein, 1989) implemented in QTLMap software. In practice, the bounds of the interval were the 2 locations where the likelihood was equal to the maximum likelihood minus $3.84\left[=\chi^{2}(1,0.05)\right]$. Significant results located within the same $4-\mathrm{Mb}$ interval were grouped into a single QTL region, as presented by Sanchez et al. (2016).

Close Linkage Versus Pleiotropism Test. Because QTL locations were found in the same genomic region for different traits, the "Close LInkage versus Pleiotropism test" (CLIP) developed by David et al. (2013) was implemented to distinguish between pleiotropy (a single QTL affecting more than one trait) and close linkage (different QTL that are physically close to each other and influence the traits). Briefly, the test uses the following equation to compare 2 traits and rejects the hypothesis of a pleiotropic QTL if the square of the observed correlation between a combination of apparent effects at the marker level is below the minimal value it can take under the pleiotropic assumption, multiplied by a factor $\mathrm{K}_{\alpha}$ :
$\hat{\rho}_{X_{1} X_{2}}^{2}<K_{\alpha}\left[\sqrt{\left(1-\frac{1}{2 N} \frac{\hat{\sigma}_{y_{1}}^{2}}{\hat{\sigma}^{2}}\right)\left(1-\frac{1}{2 N} \frac{\hat{\sigma}_{y_{1}}^{2}}{\hat{\sigma}^{2}}\right)}-\frac{1}{2 N} \frac{\hat{\sigma}_{X_{2}}^{2} \hat{\sigma}_{y_{2}}^{2}}{\hat{\sigma}^{2}{ }_{X_{1}} \hat{\sigma}^{2} X_{2}}\right]^{2}$,

where $\hat{\rho}^{2} X_{1} X_{2}$ is the observed correlation between $X_{1}$ and $X_{2}$, which are combinations of the apparent effects of the markers of the considered region on traits 1 and 2 , respectively; $\hat{\sigma}^{2} X_{1}$ and $\hat{\sigma}^{2} X_{2}$ are the observed variances of $X_{1}$ and $X_{2}$; and $\hat{\sigma}_{y_{1}}^{2}$ and $\hat{\sigma}^{2}{ }_{y_{2}}$ are the variances of the raw data. $\mathrm{K}_{\alpha}$ corresponds to the $\alpha$ th percentile of the distribution of the ratio of the square of the observed correlation to its minimal value under the pleiotropism assumption and controls the risk of wrongly concluding linkage ( $\alpha$-risk); $N$ is the number of animals. According to David et al. (2013), this test is relevant and performed only if

$$
2 N>\left(\frac{\hat{\sigma}^{2} y_{1}}{\hat{\sigma}^{2} X_{1}}+\frac{\hat{\sigma}_{y_{2}}^{2}}{\hat{\sigma}_{X_{2}}^{2}}\right) .
$$

Factor $\mathrm{K}_{\alpha}$ depends on different parameters: $N$, $\alpha$, the variance of linkage disequilibrium between the QTL and the markers, and the effect of the QTL on the phenotypic variance for each trait. In this study, we estimated $K_{\alpha}$ for each test, calculating the QTL effect on the phenotypic variance, considering the $\alpha$-risk at 
$5 \%$, and taking the default setting proposed by the software for the $\mathrm{LD}$ variance $(0.202) ; \mathrm{K}_{\alpha}$ varied from 1.13 to 1.17 .

The CLIP test was performed in the Saanen breed for a 241-SNP region located between 20 and $32 \mathrm{Mb}$ on CHI 19. Quantitative trait loci for milk production traits had previously been detected in the same genomic region of CHI 19 using the same data set (Martin et al., 2017). Indeed, QTL for milk yield (MY), protein yield $(\mathbf{P Y})$, and fat yield (FY) were mapped on CHI 19 between 22 and $29 \mathrm{Mb}$. Accordingly, the CLIP test was carried out for UFP, RUA, MY, PY, and FY. In addition, TF-for which there was no QTL in the region-was tested as a negative control.

Multi-Trait Association Mapping. The multitrait QTL on CHI 19 was further investigated using 2 approaches. First, a PCA was implemented on the 5 traits MY, FY PY, RUA, and UFP, using the SAS PRINCOMP procedure (SAS Institute Inc., 2008). The number of principal components to be retained was based on the proportion of variability explained and on their relationships with the original variables. Principal component (PC) scores were then calculated and treated as a new phenotype for performing LD QTL mapping as described above. A linear model was then fitted to the SNP that was close to the most significant position, to quantify its effect on the different traits (MIXED procedure; SAS Institute Inc., 2008). The model included the fixed effects of sire and SNP. Second, a multivariate QTL detection was implemented using LA implemented in QTLMap. In this approach developed by Gilbert and Le Roy (2003), the joint influence on the traits is assumed to follow a multinormal distribution. Significance levels were estimated by Monte Carlo simulations, with trait values being simulated with multinormal distributions (Gilbert and Le Roy, 2003).

\section{RESULTS}

\section{Descriptive Statistics}

Raw phenotypes are presented in Table 1. Mean values were similar in the 2 breeds, with an average difference between breeds of $0.2 \mathrm{SD}$. The maximum difference was equal to $0.51 \mathrm{SD}$ for TO. The LSCS were also slightly higher in Saanen than in Alpine, especially in the third parity. Also, the raw means of phenotypes in the present data set were comparable to national breed averages for contemporary Alpine goats $(\mathrm{n}=185,816$ for LSCS and 39,502 for type) and Saanen goats (n $=158,608$ for LSCS and 25,767 for type). Indeed, the average difference from the breed average was equal to
0.01 and 0.04 SD for Alpine and Saanen, respectively. The maximum departure from the national values $(+0.27 \mathrm{SD})$ was for LSCS in third parity, with slightly high cell counts (LSCS $=6.86 \pm 1.18$ ) in our Alpine sample (Table 1) compared with the national average $(\mathrm{LSCS}=6.50 \pm 1.29)$.

The results of the PCA are shown in Figure 1. The first dimension (PC1) accounted for $55 \%$ of total variance and showed substantial variation within breed, mainly related to sire families. The second dimension (PC2) summarized $8 \%$ of the variation and clearly distinguished Saanen and Alpine breeds.

\section{Genome-Wide Association for Type Traits and LSCS}

Thirty-seven QTL were detected by LA at the $1 \%$ chromosome-wide threshold (Table 2). Seven of them, located in 4 regions of chromosomes CHI 1, 6, 8, and 19, exceeded the $5 \%$ genome-wide threshold. Many more QTL were detected by association mapping, giving 222 locations (454 SNP) that exceeded the $5 \%$ genomewide threshold (see Supplemental Table S1; https:// doi.org/10.3168/jds.2017-13625). These locations were scattered all over the genome, with enrichment on CHI $6,8,14$ and 19 and with a range of 12 to 32 locations per trait.

The 4 most significant regions were especially interesting. First, a CHI 19 region showed a strong association with udder type in the Saanen breed: UFP using LA (5\% CI: 24.1-29.7 Mb; Table 2) and both UFP and RUA using LD (5\% CI: 24.4-26.4 Mb; Figure 2a, b). The QTL explained 5\% of variance for each of the 2 traits, as estimated from the single-trait LD analyses. Then, another CHI 19 region was found associated with LSCS in the Saanen breed using LA (5\% CI: 40.8-42.1 Mb; Table 2) and LD (5\% CI: 35.0-35.2 Mb). This QTL explained $4 \%$ of variance for the trait. Finally, 2 regions on CHI 6 (5\% CI: $45.8-46.0 \mathrm{Mb}$ ) and CHI 8 (5\% CI: 80.7-81.1 Mb) were found associated with $\mathrm{CD}$ in the Alpine breed using LD (Figure 2c; see Supplemental Table S1; https://doi.org/10.3168/jds.2017-13625). The QTL explained 6 and 3\% of variance for the trait, respectively.

When the 2 breeds were compared, more locations were detected in Saanen $(\mathrm{n}=73$, total number of SNP $=182)$ than in Alpine $(\mathrm{n}=55$, total number of SNP $=116$ ) goats, even though the design included more Alpine families and goats. Among those association results, only one location was shared by the 2 breeds when examined separately ( $\mathrm{TF}$ at 73.2 and $77 \mathrm{Mb}$ on CHI 14). The significant positions detected for the 2 breeds analyzed jointly were either new regions (not found in the single-breed analysis) or regions shared 
Table 2. Linkage-based genome scan (LA) for 11 type traits and lactation SCS (LSCS) in 1,941 dairy goats ${ }^{1}$

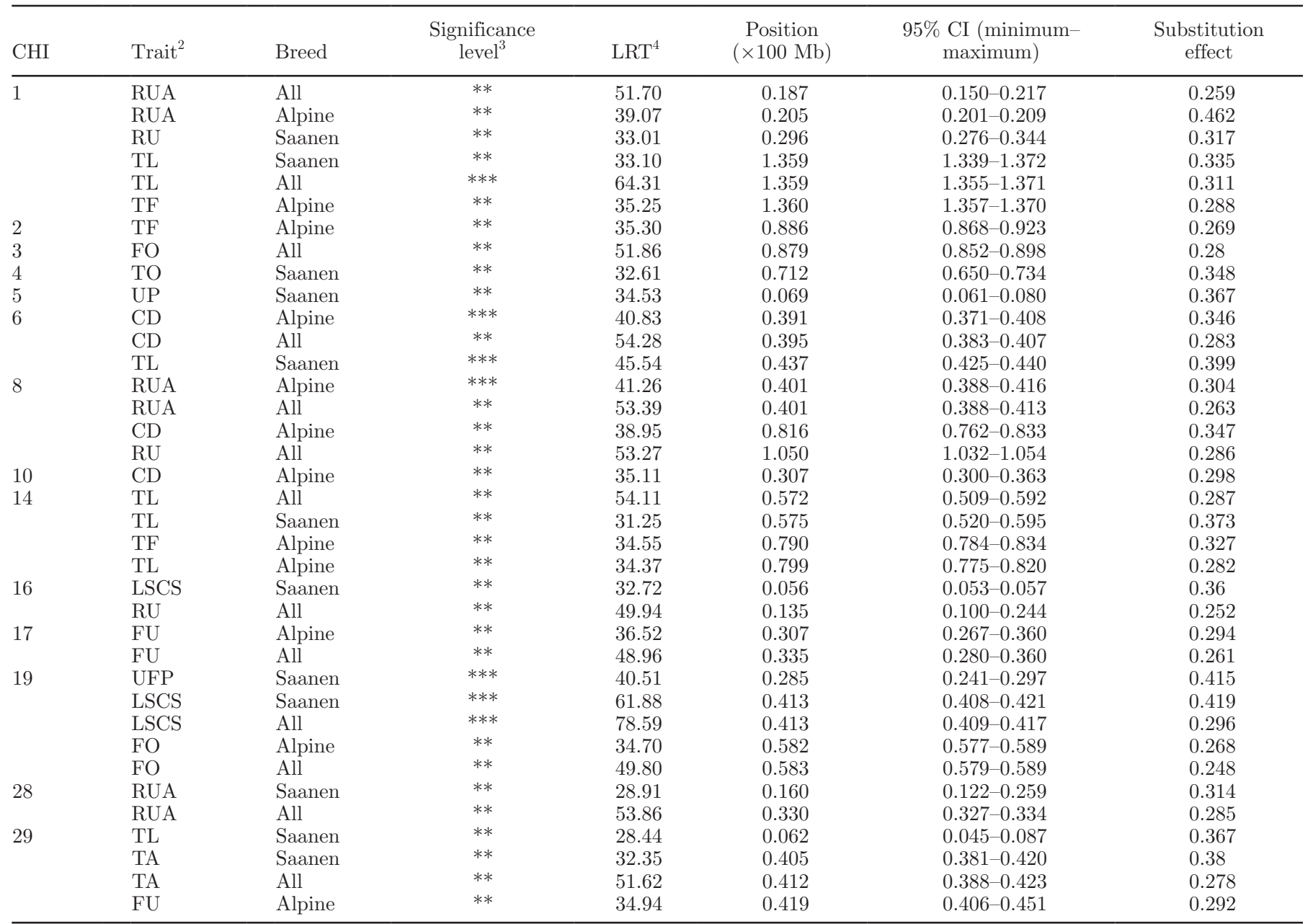

${ }^{1}$ QTL were mapped separately by breed (Alpine, $\mathrm{n}=787$; Saanen, $\mathrm{n}=1,154$ ) and combined in a joint analysis (All). Results were ordered by chromosome (CHI, Capra hircus) and position.

${ }^{2} \mathrm{FU}=$ fore udder; $\mathrm{UP}=$ udder profile; $\mathrm{UFP}=$ udder floor position; $\mathrm{TL}=$ teat length; $\mathrm{TF}=$ teat form; $\mathrm{TA}=$ teat angle; $\mathrm{TO}=$ teat orientation; $\mathrm{RU}=$ rear udder; RUA $=$ rear udder attachment; $\mathrm{CD}=$ chest depth; and $\mathrm{FO}=$ foot orientation.

${ }^{3}$ Significance level: ${ }^{* * *}=5 \%$ genome-wide; ${ }^{* *}=1 \%$ chromosome-wide. The $95 \%$ CI of the QTL locations were estimated by logarithm of odds drop-off.

${ }^{4}$ Likelihood ratio test.

with 1 of the 2 breeds. In most cases, the results from the 2 breeds combined in a joint analysis did not strengthen the single-breed results, but there were 2 exceptions. First, the significance of the QTL for LSCS on CHI 19 using LA (Table 2) was higher when both breeds were analyzed jointly. Similarly, the significance of the QTL for TL on CHI 1 based on LA (Table 2) was increased when both breeds were analyzed jointly.

\section{Testing for Pleiotropy on CHI 19 in Saanen}

The CLIP test was performed for UFP, RUA, MY, $\mathrm{PY}, \mathrm{FY}$, and TF traits in the CHI 19 QTL region (20-32 Mb) to determine whether those QTL were a single pleiotropic QTL or different QTL in close linkage. The results are presented in Supplemental Table S2 (https://doi.org/10.3168/jds.2017-13625). As expected, the negative control TF always showed a rejection of pleiotropy with RUA, UFP, MY, FY, and PY. In contrast, the pleiotropic assumption $\left(\mathrm{H}_{0}\right)$ was never rejected in any of the 2-trait analyses with RUA, UFP, MY, FY, and PY, except for RUA-FY. The observed correlation (0.52), however, was only slightly below the threshold (0.54) at which the hypothesis of pleiotropy was rejected. This suggests that all of these traits may be controlled by the same gene(s) or by genes too close together on the genome to be distinguished by our design. 

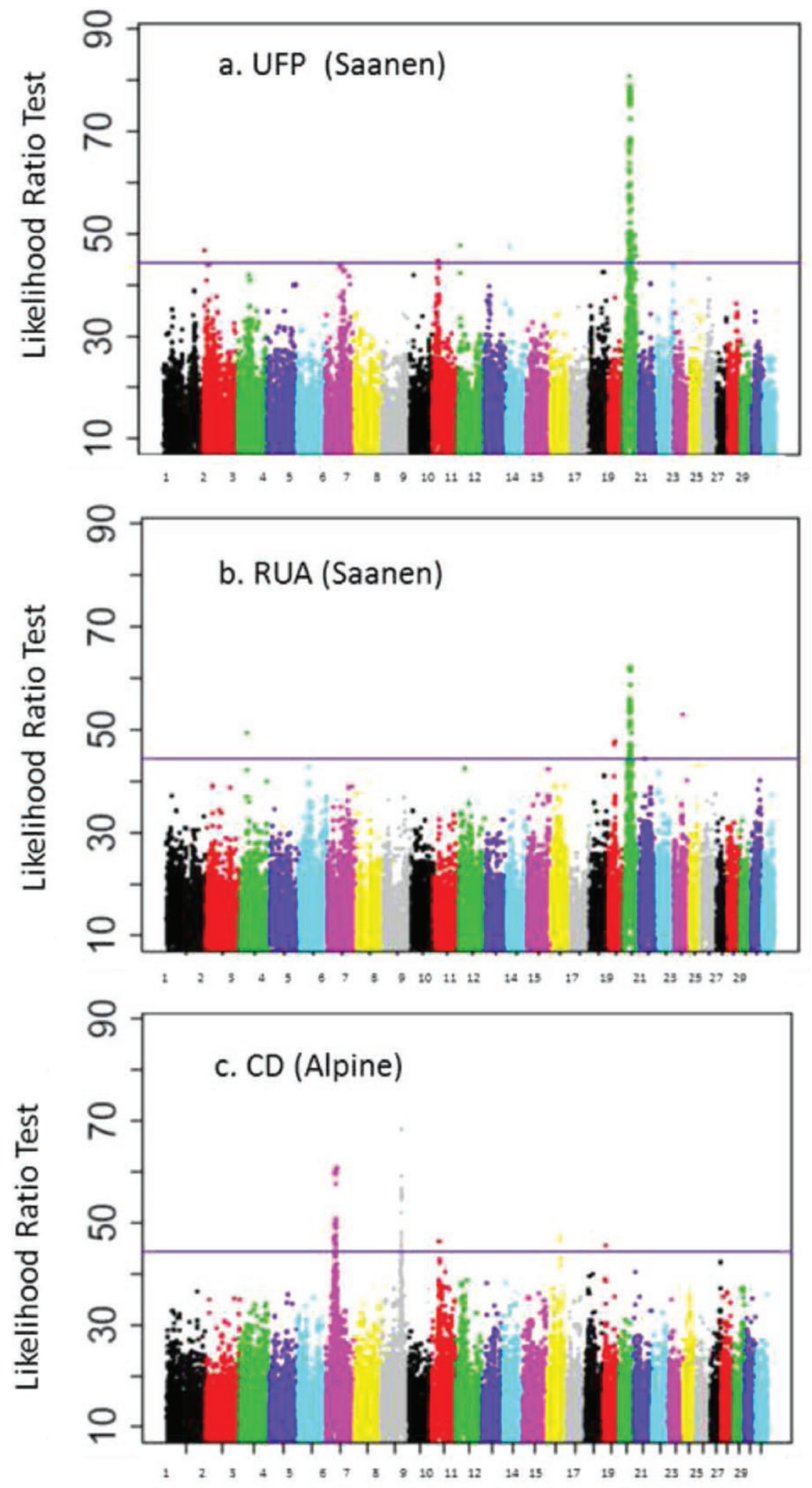

Chromosome

Figure 2. Manhattan plot of likelihood ratio test profiles show 3 highly significant QTL for 3 type traits: (a) udder floor position (UFP) in Saanen, (b) rear udder attachment (RUA) in Saanen, (c) chest depth (CD) in Alpine. Color version available online. 
Results from the single-trait approach using LD are presented in Figure 3a, and results from the multi-trait approaches using LA and LD are presented in Figure $3 \mathrm{~b}$. The PCA for the 5 traits provided a value on the first component (PC1) that explained $57 \%$ of the overall variance. The correlation of $\mathrm{PC} 1$ with $\mathrm{MY}, \mathrm{FY}$, PY, RUA, and UFP was $0.91,0.91,0.94,-0.29$, and -0.48 respectively. The $\mathrm{LD}$ analysis for $\mathrm{PC} 1$ on $\mathrm{CHI}$ 19 showed a higher LRT estimate than for the traits analyzed separately (Figure 3a, b). The LD analysis for $\mathrm{PC} 1$ also reduced the length of the confidence interval to $2.4 \mathrm{Mb}(5 \% \mathrm{CI}=24.5-26.9 \mathrm{Mb})$ compared with the $4.2-\mathrm{Mb}$ cumulative interval obtained from the 5 separate analyses $(5 \% \mathrm{CI}=22.2-26.4 \mathrm{Mb})$. The SNP with the highest significance level (highest LRT) was snp10622-scaffold1377-956913 (rs268243476), with minor allele frequency of 0.21 .

The latter SNP was fitted into a linear model to quantify its effect on the 5 traits. The model also included the fixed sire effect. The results are presented in Supplemental Table S3a (https://doi.org/10.3168/ jds.2017-13625). The SNP had an opposite effect on milk production and udder type. Indeed, the genotype associated with higher MY, FY, and PY was associated with lower (unfavorable) scores for RUA and UFP; that is, less strongly attached and lower udder floor position, respectively. This result was in agreement with the negative correlation between the phenotypes
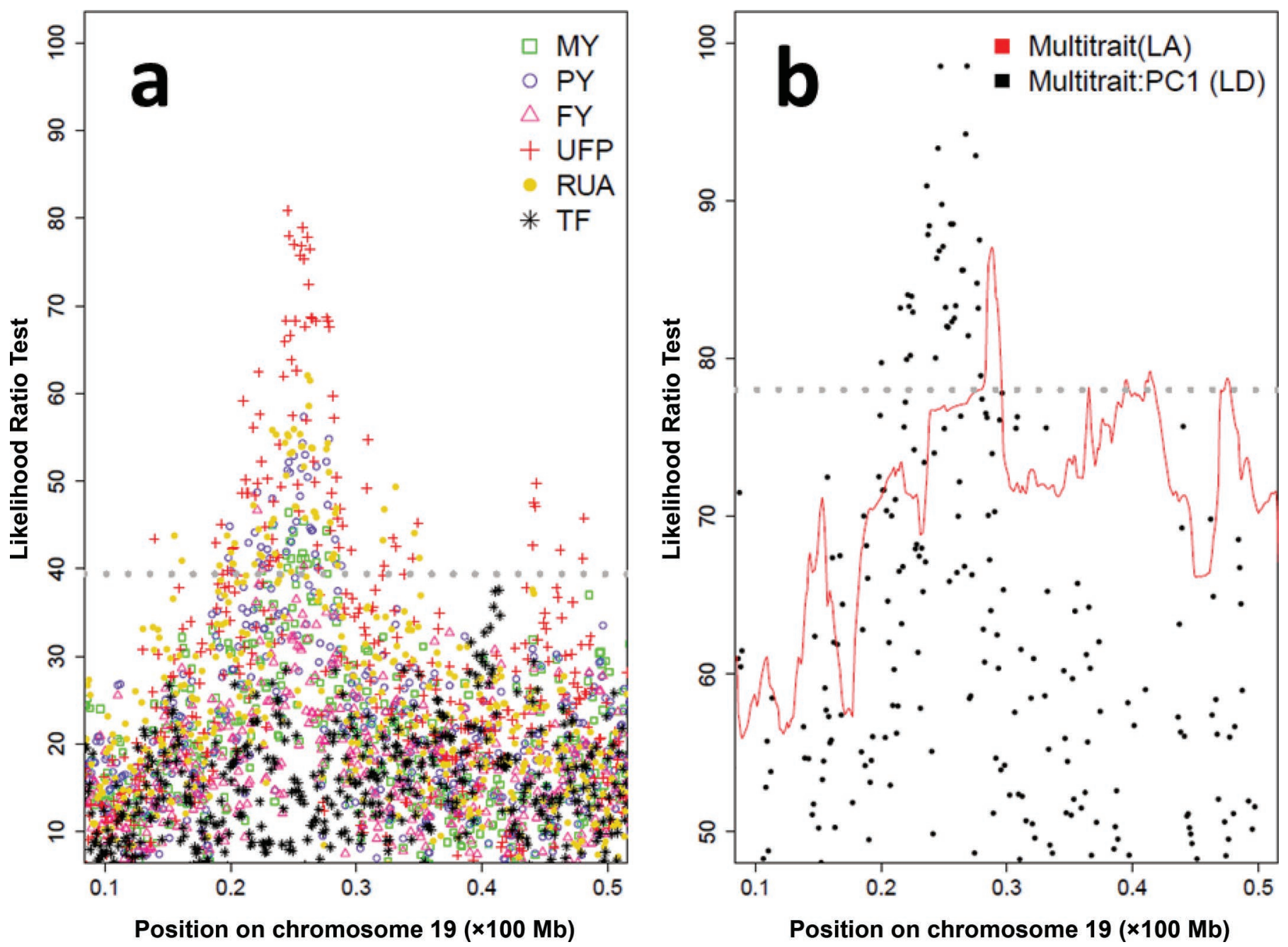

Figure 3. Global likelihood ratio test profiles on Capra hircus chromosome 19 (CHI19) in the Saanen breed show significant effect of the same region on 5 traits. Results were based on (a) association analyses for udder floor position (UFP), rear udder attachment (RUA), teat form (TF), milk production (MY), fat yield (FY), and protein yield (PY); and (b) multitrait linkage analysis (LA; curve) and association analysis (linkage disequilibrium, LD) for the principal component trait PC1 (ם). The PC1 was from a principal component analysis carried out on the 5 MY, FY, PY, RUA, and UFP traits, using the SAS PRINCOMP procedure (SAS Institute, 2008). The horizontal dotted line represents the $5 \%$ genome-wide threshold. Color version available online. 
(Supplemental Table S3b; https://doi.org/10.3168/jds .2017-13625).

The multi-trait approach using LA in QTLMap similarly increased the LRT value $(\mathrm{LRT}=87.05)$ compared with single LA analyses (Figure 3b). The latter approach additionally provided the relative effect of the QTL on the 5 traits, equal to $0.31,0.24,0.31,-0.33$, and -0.42 SD for MY, FY, PY, RUA, and UFP, respectively. The QTL explained 3 to $5 \%$ of phenotypic variance (yield deviation) for each of the 5 traits, as estimated from the single-trait LD analyses.

\section{DISCUSSION}

\section{Type and LSCS Traits Are Mostly Under Polygenic Control in Dairy Ruminants}

A large number of QTL for type and LSCS have been mapped on the 29 caprine autosomes $(>220)$. With this study including health data, it is possible that some of the associations would appear on chromosome $\mathrm{X}$. The present method and software chosen, however, based on within-founder regressions (large families of male founders) were not well suited to analyze the X chromosome. This could be done in the future using alternative methods such as association mapping in females with polygenic models, with full pedigree or genomic parentage matrix to account for the population stratification.
It is interesting to note that among the numerous QTL regions for type and LSCS traits reported in the cattle literature (http://www.animalgenome.org/cgi -bin/QTLdb), several studies have pointed to the same syntenic regions for the same - or similar-traits. In particular, Cole et al. (2011) investigated 31 production, health, reproduction, and type traits in Holstein using a 50K SNP chip and highlighted a large number of genomic regions associated with these traits. The study by Pausch et al. (2016) identified 12 QTL for udder morphology using a combination of a $634 \mathrm{~K}$ SNP chip and sequence data in Fleckvieh. Among those bovine results, we found syntenic regions (Table 3). Earlier studies in cattle had also reported QTL for udder type and LSCS (Bennewitz et al., 2004; Schrooten et al., 2004; Ashwell et al., 2005). However, the latter studies were based on low-density marker panels (microsatellites) and the confidence intervals for these QTL were large. Altogether, the present study and literature data indicate a polygenic control of type and LSCS traits in dairy species, with some possible commonalities across cattle and goat.

\section{Two Goat Breeds with Different Genetic Control}

Most loci associated with type traits and LSCS in dairy goats were on different chromosomes or at different positions in the 2 breeds studied separately. These

Table 3. Concordant QTL with literature data

\begin{tabular}{|c|c|c|c|c|c|c|}
\hline \multicolumn{3}{|c|}{ Caprine QTL } & \multicolumn{4}{|c|}{ Concordant bovine QTL in syntonic regions } \\
\hline $\mathrm{CHI}^{1}$ & Position (Mb) & Trait $^{2}$ & BTA & Position (Mb) & Trait & Reference $^{3}$ \\
\hline 1 & $18.6-20.4$ & RUA & 1 & 16.9 & Udder cleft & Cole et al. (2011) \\
\hline 1 & 29.5 & RUA & 1 & $\begin{array}{l}28.4 \\
39^{4}[24-40]\end{array}$ & $\begin{array}{l}\text { Dairy form teat length } \\
\text { Udder cleft }\end{array}$ & $\begin{array}{l}\text { Cole et al. (2011) } \\
\text { Schnabel et al. (2005) }\end{array}$ \\
\hline 3 & 87.9 & $\mathrm{FO}$ & 3 & 88.6 & Foot angle & Cole et al. (2011) \\
\hline 5 & 6.9 & UP & 5 & 7 & Udder cleft, rear teat placement & Cole et al. (2011) \\
\hline 6 & 45.9 & $\mathrm{CD}$ & 6 & $41.7-45$ & Stature, body depth & Cole et al. (2011) \\
\hline 11 & 13.2 & TO & 11 & 18.7 & Teat placement, central ligament & Pausch et al. (2016) \\
\hline 17 & $30.7-33.5$ & $\mathrm{FU}$ & 17 & 34 & Udder depth, stature & Cole et al. (2011) \\
\hline 17 & 58.6 & RUA & 11 & 62.7 & $\begin{array}{l}\text { Central ligament, fore udder length, } \\
\text { teat thickness and placement }\end{array}$ & Pausch et al. (2016) \\
\hline 19 & $24.5-28.5$ & UFP, RUA & 19 & 35 & Udder depth & Schrooten et al. (2004) \\
\hline 19 & 41.33 & LSCS & 19 & $58^{4}[7-130]$ & SCS & Bennewitz et al. (2004) \\
\hline 26 & 42.26 & TL & 26 & 46 & Teat thickness & Pausch et al. (2016) \\
\hline 29 & 12.55 & $\mathrm{FO}$ & 29 & $3.2^{4}[1-49]$ & Foot angle & Ashwell et al. (2005) \\
\hline 29 & $40.4-41.8$ & $\mathrm{TA}$ & 29 & $\begin{array}{l}14.6-15.9 \\
13-21^{4}[1-49]\end{array}$ & $\begin{array}{l}\text { Foot angle } \\
\text { Rear udder width, rear udder height, } \\
\text { fore udder attachment, front teat } \\
\text { placement }\end{array}$ & $\begin{array}{l}\text { Cole et al. (2011) } \\
\text { Ashwell et al. (2005) }\end{array}$ \\
\hline
\end{tabular}

\footnotetext{
${ }^{1}$ Capra hircus autosome.

${ }^{2} \mathrm{RUA}=$ rear udder attachment; $\mathrm{FO}=$ foot orientation; $\mathrm{UP}=$ udder profile; $\mathrm{CD}=$ chest depth; $\mathrm{TO}=$ teat orientation; $\mathrm{FU}=$ fore udder; $\mathrm{UFP}$ $=$ udder floor position; LSCS = lactation SCS; TL = teat length; TA = teat angle.

${ }^{3}$ Cole et al. (2011): Holstein cattle, 50K SNP chip; Schnabel et al. (2005): Holstein cattle, 221 microsatellites; Pausch et al. (2005): Fleckvieh cattle, 634K SNP chip and sequence data; Schrooten et al. (2004): Holstein cattle, 277 microsatellites; Bennewitz et al. (2004): Holstein cattle, 127 microsatellites on 9 chromosomes; Ashwell et al. (2005): Holstein cattle, 406 microsatellites.

${ }^{4}$ Large confidence interval in brackets (low marker density; i.e., microsatellites).
} 
results suggest that the genes responsible for those traits, or allele frequencies, truly differ between the 2 breeds. Our aim in combining the 2 breeds was to increase the power and thereby detect those loci that showed consistent associations across the 2 breeds. This approach resulted mostly in the identification of new locations not previously found within the breed. Therefore, SNP detected by the joint breed analyses are likely linked with shared loci, each having a consistent but small effect on the SNP within each breed. This observation is in accordance with previous QTL in the same breeds for supernumerary teats (Martin et al., 2016a) and milk production traits (Martin et al., 2017), which showed that QTL locations were shared across Saanen and Alpine only for some traits (protein and fat content) and that genetic control for other traits was essentially different. Pure breed selection in French dairy goats began in the 1960s. The breeding objectives initially focused on milk production and then included udder type in 2006 (Clément et al., 2002) and LSCS in 2013 (Clément et al., 2016). The same breeding objective has been applied over the past $50 \mathrm{yr}$ to both Saanen and Alpine goat breeds, and descriptive statistics show overall similar raw data for these traits between the breeds in the current data set as well as in previous research (Rupp et al., 2011). Only teat traits were slightly different between breeds; teats are longer and more vertical in Saanen than in Alpine. Despite similar patterns and breeding goals, a level of genetic heterogeneity in the determinism of dairy-related traits is therefore apparent, which may reflect original breed differences, genetic drift, or both.

\section{A Promising Region with Candidate Genes for LSCS on CHI 19 in Saanen}

In the Saanen breed, a highly significant QTL for LSCS was found on CHI 19 (33-42 Mb). Of note, a dairy sheep study based on a 50K SNP chip (Rupp et al., 2015) pointed to the same syntenic region located on Ovis aries chromosome (OAR) 11 for LSCS. However, the latter QTL, in both goat and sheep, showed a large overlapping confidence interval when the LA and $\mathrm{LD}$ results were considered together $(>5 \mathrm{Mb}$ interval), indicating that comparative mapping might not be suitable for narrowing down the causative genes. Also, the region is particularly gene-enriched, making the nomination of candidate genes difficult. However, 4 genes located within the confidence interval of the caprine QTL are good functional candidates. The retinoic acid receptor $\alpha(R A R A)$ gene, located at $39.8 \mathrm{Mb}$, is differently expressed in divergent mastitis-resistant and mastitis-susceptible lines of sheep (Bonnefont et al., 2011).
This gene regulates the expression of target genes and is involved in various biological processes. In addition, 3 genes related to signal transducers and activators of the transcription family are located at 41-42 Mb: STAT3, $S T A T 5 B$, and STAT5B. This gene family belongs to the Janus kinase (JAK/STAT) signaling pathway, known for its importance in the immune response and its relation to mastitis susceptibility in both cattle (Usman et al., 2014) and sheep (Rupp et al., 2015). This QTL was not found in the Alpine breed. However, the QTL significance using LA was increased when both breeds were analyzed jointly, suggesting that although it was not significant at the $5 \%$ chromosome-wide threshold, the QTL is also segregating in this breed.

\section{A Pleiotropic QTL for Milk and Udder Type on $\mathrm{CHI} 19$ in Saanen}

Another region of CHI 19 (24.5-27 Mb) was associated with both type (RUA and UFP) and milk production traits (MY, FY, and PY) in the Saanen breed. The allele with the highest frequency had an adverse effect, improving milk production while deteriorating udder shape. The question was raised as to whether the QTL was a single pleiotropic QTL or different QTL in close linkage. Results from the CLIP test suggested that that a single pleiotropic QTL affected all of these traits. Regarding the 2 udder type traits, this is in agreement with the high genetic correlation between these traits; that is, 0.74 and 0.71 in the Saanen and Alpine breeds, respectively (Clément et al., 2006), suggesting that they are, in large part, the expression of the same trait. However, among the 10 and 5 significant regions for UFP and RUA, respectively, found in the 2 breeds (Supplemental Table S1; https://doi.org/10.3168/jds .2017-13625), only the one on CHI 19 region in Saanen was common ( $<2 \mathrm{Mb}$ apart). This QTL, therefore, explains only a small part of the genetic correlation between traits, which is also high in Alpine goats. The result from the CLIP test is also in agreement with a direct biological link between udder shape and milk production. To further confirm the result of pleiotropy at this locus, it would be interesting to rerun the test with an increased number of SNP in this region such that the variance of linkage disequilibrium between the QTL and the markers is increased. As additional SNP in the CHI 19 region were added to a custom-built chip used for parentage assessment, new genotypes and animals will be available in the near future to conduct such a validation.

From a functional perspective, we can reasonably hypothesize that the same gene can affect both milk production and udder size and shape. Martin et al. 
(2017), who first described the QTL on CH19 for milk production, suggested a few possible candidate genes related to fatty acid and lipid metabolism pathways: phospholipase D2 (PLD2), gamma-glutamyltransferase $6(G G T 6)$, and arachidonate lipoxygenase $(A L O X)-12$, $-12 \mathrm{~B}$, and -15 . However, the function of those genes is unlikely to be related to udder type. As mentioned above, CHI 19 is highly enriched in genes, with an average of 22.5 genes $/ \mathrm{Mb}$, making the nomination of candidate genes difficult. In the pleiotropic QTL region, the density is even higher, with 308 known genes within a $12-\mathrm{Mb}$-long region. In comparison, a mean of 9.6 genes/ $\mathrm{Mb}$ was found across the entire genome, according to the National Center for Biotechnology Information goat genome data (https://www.ncbi.nlm.nih.gov/ genome?term=capra\%20hircus). Further fine mapping and functional analyses are, therefore, needed to identify the causative gene(s) and variant(s). Indeed, to our knowledge, this is the only way to determine whether one or several variants of the regions are responsible for the phenotypes we observe. As stated previously, genotypes on new animals for SNP in this region will be available in the near future thanks to a custom-built chip. Also, whole-genome sequence data for a few dozen Saanen animals will be available in the Vargoats project (http://www.goatgenome.org/vargoats.html). This data might help in fine mapping the QTL, possibly using imputation from $50 \mathrm{~K}$ to sequence.

The present results may explain some part of the adverse genetic correlation between udder type and milk production that exists in our goat populations. Indeed, genetic correlations $\left(\mathrm{r}_{\mathrm{g}}\right)$ between milk production and $\mathrm{UFP}\left(\mathrm{r}_{\mathrm{g}}=-0.55\right.$ in Saanen vs. $\mathrm{r}_{\mathrm{g}}=-0.43$ in Alpine) or between milk production and RUA $\left(\mathrm{r}_{\mathrm{g}}=-0.31\right.$ in Saanen vs. $r_{g}=-0.17$ in Alpine) are high and stronger in the Saanen breed than in the Alpine breed (Clément et al., 2006). This genetic opposition and deterioration of udder shape motivated the inclusion of udder type traits in the breeding objective of French Saanen and Alpine goats in 2006 (Clément et al., 2002). However, if the genetic opposition between udder type and production in Saanen is caused, at least in part, by a genetic variant with pleiotropic effects, it cannot be disrupted by conventional or SNP-assisted selection. The simultaneous improvement of udder shape and milk production might thus be limited. We will therefore need to conduct further fine-mapping analyses to address this issue. The present findings and other dairy literature (Fasquelle et al., 2009; Kadri et al., 2014; Rupp et al., 2015) add to the evidence that pleiotropy and tradeoffs are not uncommon in commercially bred livestock. They highlight the need for knowledge and methods on how to achieve the optimal balancing selection for both functional traits and production traits in livestock when close linkage or specific variants with pleiotropic effects are identified.

\section{CONCLUSIONS}

We present a genome-wide association study that highlighted a large number of QTL regions for type and health (LSCS) traits in dairy goats. Genomic control of those traits was mostly polygenic and breed-specific, suggesting that within-breed selection should be favored for those traits. Goat chromosome 19 displayed a large concentration of SNP effects. One region was significantly associated with LSCS in Saanen, close to candidate genes that could be involved in the response to intramammary infection (RARA, STAT3, STAT5A, and $S T A T 5 B)$. Another region of the chromosome showed an adverse pleiotropic effect on milk production and udder traits. These results will be helpful for goat selection in the future and could lead to the identification of causal mutations.

\section{ACKNOWLEDGMENTS}

The authors thank Pierre Martin and the Capgenes (Mignaloux Beauvoir, France) breeding organizations for the data provided and their helpful contributions. This work was supported by grants from French organizations through "Genomcap" [a research program including INRA, APIS-GENE, Union Nationale des Cooperatives d'Elevage et d'Insemination Animale (UNCEIA), Capgenes, and France Conseil Elevage (FCEL)] and EC (FP7/2007-2013), grant no. 245140, "3SR," Sustainable Solutions for Small Ruminants (http://www.3srbreeding.eu/). The authors thank the involved partners. Cyrielle Maroteau received the support of the Union Nationale des Cooperatives d'Elevage et d'Insémination Animale (UNCEIA), Apis-gene, and Capgenes for her CIFRE scholarship. Pauline Martin acknowledges the support of Région Midi-Pyrénées, Animal Genetics Department from INRA and GENOMCAP research program including INRA, APISGENE, ALLICE (formerly UNCEIA), and FCEL (all located in Paris, France) and CAPGENE (MignalouxBeauvoir, France).

\section{REFERENCES}

Ali, A. K. A., and G. E. Shook. 1980. An optimum transformation for somatic cell concentration in milk. J. Dairy Sci. 63:487-490. https://doi.org/10.3168/jds.S0022-0302(80)82959-6.

Ashwell, M. S., D. W. Heyen, J. I. Weller, M. Ron, T. S. Sonstegard, C. P. Van Tassell, and H. A. Lewin. 2005. Detection of quantitative trait loci influencing conformation traits and calving ease in 
Holstein-Friesian cattle. J. Dairy Sci. 88:4111-4119. https://doi .org/10.3168/jds.S0022-0302(05)73095-2.

Bennewitz, J., N. Reinsch, V. Guiard, S. Fritz, H. Thomsen, C. Looft, C. Kühn, M. Schwerin, C. Weimann, G. Erhardt, F. Reinhardt, R. Reents, D. Boichard, and E. Kalm. 2004. Multiple quantitative trait loci mapping with cofactors and application of alternative variants of the false discovery rate in an enlarged granddaughter design. Genetics 168:1019-1027. https://doi.org/10.1534/genetics .104 .030296 .

Bonnefont, C. M., M. Toufeer, C. Caubet, E. Foulon, C. Tasca, M.-R. Aurel, D. Bergonier, S. Boullier, C. Robert-Granié, G. Foucras, and R. Rupp. 2011. Transcriptomic analysis of milk somatic cells in mastitis resistant and susceptible sheep upon challenge with Staphylococcus epidermidis and Staphylococcus aureus. BMC Genomics 12:208. https://doi.org/10.1186/1471-2164-12-208.

Churchill, G. A., and R. W. Doerge. 1994. Empirical threshold values for quantitative trait mapping. Genetics 138:963-971.

Clément, V., D. Boichard, A. Piacère, A. Barbat, and E. Manfredi. 2002. Genetic evaluation of French goats for dairy and type traits. Pages 119-122 in Proc. 7th Congr. Genet. Appl. Livest. Prod. Montpellier, France.

Clément, V., R. De Crémoux, H. Caillat, C. Huau, F. Bouvier, I. Palhière, H. Larroque, P. Martin, and R. Rupp. 2016. Somatic cell counts as a selection criterion for goat mastitis resistance. In Proc. 6th Int. Mastitis Conf., Nantes, France. https://prodinra.inra.fr/ ?locale $=$ en \#!ConsultNotice:371227.

Clément, V., P. Martin, and F. Barillet. 2006. Elaboration d'un index synthétique caprin combinant les caractères laitiers et des caractères de morphologie mammaire. Page 13èmes. Rencontres Recherches Ruminants, Paris, France.

Cole, J. B., G. R. Wiggans, L. Ma, T. S. Sonstegard, T. J. Lawlor, B. A. Crooker, C. P. Van Tassell, J. Yang, S. Wang, L. K. Matukumalli, and Y. Da. 2011. Genome-wide association analysis of thirty one production, health, reproduction and body conformation traits in contemporary U.S. Holstein cows. BMC Genomics 12:408. https://doi.org/10.1186/1471-2164-12-408.

David, I., J.-M. Elsen, and D. Concordet. 2013. CLIP Test: A new fast, simple and powerful method to distinguish between linked or pleiotropic quantitative trait loci in linkage disequilibria analysis. Heredity 110:232-238. https://doi.org/10.1038/hdy.2012.70.

Dong, Y., M. Xie, Y. Jiang, N. Xiao, X. Du, W. Zhang, G. TosserKlopp, J. Wang, S. Yang, J. Liang, W. Chen, J. Chen, P. Zeng, Y. Hou, C. Bian, S. Pan, Y. Li, X. Liu, W. Wang, B. Servin, B. Sayre, B. Zhu, D. Sweeney, R. Moore, W. Nie, Y. Shen, R. Zhao, G. Zhang, J. Li, T. Faraut, J. Womack, Y. Zhang, J. Kijas, N. Cockett, X. Xu, S. Zhao, J. Wang, and W. Wang. 2013. Sequencing and automated whole-genome optical mapping of the genome of a domestic goat (Capra hircus). Nat. Biotechnol. 31:135-141. https://doi.org/10.1038/nbt.2478.

Elsen, J.-M., B. Mangin, B. Goffinet, D. Boichard, and P. Le Roy. 1999. Alternative models for QTL detection in livestock. I. General introduction. Genet. Sel. Evol. 31:213-224. https://doi.org/10 .1186/1297-9686-31-3-213.

Fasquelle, C., A. Sartelet, W. Li, M. Dive, N. Tamma, C. Michaux, T. Druet, I. J. Huijbers, C. M. Isacke, W. Coppieters, M. Georges, and C. Charlier. 2009. Balancing selection of a frame-shift mutation in the MRC2 gene accounts for the outbreak of the Crooked Tail Syndrome in Belgian Blue cattle. PLoS Genet. 5:e1000666. https://doi.org/10.1371/journal.pgen.1000666.

Gilbert, H., and P. Le Roy. 2003. Comparison of three multitrait methods for QTL detection. Genet. Sel. Evol. 35:281-304. https://doi .org/10.1051/gse:2003009.

Kadri, N. K., G. Sahana, C. Charlier, T. Iso-Touru, B. Guldbrandtsen, L. Karim, U. S. Nielsen, F. Panitz, G. P. Aamand, N. Schulman, M. Georges, J. Vilkki, M. S. Lund, and T. Druet. 2014. A 660-kb deletion with antagonistic effects on fertility and milk production segregates at high frequency in Nordic Red cattle: Additional evidence for the common occurrence of balancing selection in livestock. PLoS Genet. 10:e1004049. https://doi.org/10.1371/journal .pgen.1004049.
Kijas, J. W., J. S. Ortiz, R. McCulloch, A. James, B. Brice, B. Swain, G. Tosser-Klopp, and International Goat Genome Consortium. 2013. Genetic diversity and investigation of polledness in divergent goat populations using 52088 SNPs. Anim. Genet. 44:325-335. https://doi.org/10.1111/age.12011

Knott, S. A., J. M. Elsen, and C. S. Haley. 1996. Methods for multiple-marker mapping of quantitative trait loci in half-sib populations. Theor. Appl. Genet. 93:71-80. https://doi.org/10.1007/ BF00225729.

Lander, E. S., and D. Botstein. 1989. Mapping Mendelian factors underlying quantitative traits using RFLP linkage maps. Genetics 121:185-199.

Legarra, A., and R. L. Fernando. 2009. Linear models for joint association and linkage QTL mapping. Genet. Sel. Evol. 41:43. https:// doi.org/10.1186/1297-9686-41-43.

Manfredi, E., A. Piacere, P. Lahaye, and V. Ducrocq. 2001. Genetic parameters of type appraisal in Saanen and Alpine goats. Livest. Prod. Sci. 70:183-189. https://doi.org/10.1016/S0301 $-6226(01) 00180-4$

Marnet, P. G., and B. C. McKusick. 2001. Regulation of milk ejection and milkability in small ruminants. Livest. Prod. Sci. 70:125-133. https://doi.org/10.1016/S0301-6226(01)00205-6.

Marrube, G., E. M. Cano, D. L. Roldán, F. Bidinost, M. Abad, D. Allain, D. Vaiman, H. Taddeo, and M. A. Poli. 2007. QTL affecting conformation traits in Angora goats. Small Rumin. Res. 71:255-263. https://doi.org/10.1016/j.smallrumres.2006.07.008.

Martin, P., I. Palhière, C. Maroteau, P. Bardou, K. Canale-Tabet, J. Sarry, F. Woloszyn, J. Bertrand-Michel, I. Racke, H. Besir, R. Rupp, and G. Tosser-Klopp. 2017. A genome scan for milk production traits in dairy goats reveals two new mutations in Dgat1 reducing milk fat content. Sci. Rep. 7:1872 https://doi.org/10.1038/ s41598-017-02052-0.

Martin, P., I. Palhière, G. Tosser-Klopp, and R. Rupp. 2016a. Heritability and genome-wide association mapping for supernumerary teats in French Alpine and Saanen dairy goats. J. Dairy Sci. 99:8891-8900. https://doi.org/10.3168/jds.2016-11210.

Martin, P. M., I. Palhière, A. Ricard, G. Tosser-Klopp, and R. Rupp. 2016b. Genome wide association study identifies new loci associated with undesired coat color phenotypes in Saanen goats. PLoS One 11:e0152426. https://doi.org/10.1371/journal.pone.0152426.

Palhière, I., V. Clément, I. Croue, and D. Pinard. 2015. Un objectif de sélection qui augmente le profit des éleveurs caprins. Page 22e. Journées des Rencontres Recherches Ruminants, Paris, France.

Pausch, H., R. Emmerling, H. Schwarzenbacher, and R. Fries. 2016. A multi-trait meta-analysis with imputed sequence variants reveals twelve QTL for mammary gland morphology in Fleckvieh cattle. Genet. Sel. Evol. 48:14. https://doi.org/10.1186/s12711-016-0190 -4 .

Purcell, S., B. Neale, K. Todd-Brown, L. Thomas, M. A. R. Ferreira, D. Bender, J. Maller, P. Sklar, P. I. W. de Bakker, M. J. Daly, and P. C. Sham. 2007. PLINK: A tool set for whole-genome association and population-based linkage analysis. Am. J. Hum. Genet. $81: 559-575$.

Reber, I., I. Keller, D. Becker, C. Flury, M. Welle, and C. Drögemüller. 2015. Wattles in goats are associated with the FMN1/GREM1 region on chromosome 10. Anim. Genet. 46:316-320. https://doi .org/10.1111/age.12279.

Rupp, R., V. Clément, A. Piacere, C. Robert-Granié, and E. Manfredi. 2011. Genetic parameters for milk somatic cell score and relationship with production and udder type traits in dairy Alpine and Saanen primiparous goats. J. Dairy Sci. 94:3629-3634. https://doi .org/10.3168/jds.2010-3694.

Rupp, R., and G. Foucras. 2010. Genetics of mastitis in dairy ruminants. Pages 183-212 in Breeding for Disease Resistance in Farm Animals. S. C. Bishop, R. F. E. Axford, F. W. Nicholas, J. B. Owen, ed. CABI, Wallingford, UK.

Rupp, R., P. Senin, J. Sarry, C. Allain, C. Tasca, L. Ligat, D. Portes, F. Woloszyn, O. Bouchez, G. Tabouret, M. Lebastard, C. Caubet, G. Foucras, and G. Tosser-Klopp. 2015. A point mutation in suppressor of cytokine signalling 2 (Socs2) increases the susceptibil- 
ity to inflammation of the mammary gland while associated with higher body weight and size and higher milk production in a sheep model. PLoS Genet. 11:e1005629 https://doi.org/10.1371/journal .pgen.1005629.

Sanchez, M. P., A. Govignon-Gion, M. Ferrand, M. Gelé, D. Pourchet, Y. Amigues, S. Fritz, M. Boussaha, A. Capitan, D. Rocha, G. Miranda, P. Martin, M. Brochard, and D. Boichard. 2016. Wholegenome scan to detect quantitative trait loci associated with milk protein composition in 3 French dairy cattle breeds. J. Dairy Sci. 99:8203-8215. https://doi.org/10.3168/jds.2016-11437.

SAS Institute Inc. 2008. SAS/STAT 9.2 User's Guide. SAS Institute Inc., Cary, NC.

Schnabel, R. D., T. S. Sonstegard, J. F. Taylor, and M. S. Ashwell. 2005. Whole-genome scan to detect QTL for milk production, conformation, fertility and functional traits in two US Holstein families. Anim. Genet. 36:408-416. https://doi.org/10.1111/j.1365 $-2052.2005 .01337 . x$
Schrooten, C., M. C. M. Bink, and H. Bovenhuis. 2004. Whole genome scan to detect chromosomal regions affecting multiple traits in dairy cattle. J. Dairy Sci. 87:3550-3560. https://doi.org/10.3168/ jds.S0022-0302(04)73492-X.

Tosser-Klopp, G., P. Bardou, O. Bouchez, C. Cabau, R. Crooijmans, Y. Dong, C. Donnadieu-Tonon, A. Eggen, H. C. M. Heuven, S. Jamli, A. J. Jiken, C. Klopp, C. T. Lawley, J. McEwan, P. Martin, C. R. Moreno, P. Mulsant, I. Nabihoudine, E. Pailhoux, I. Palhière, R. Rupp, J. Sarry, B. L. Sayre, A. Tircazes, J. Wang, W. Wang, W. Zhang, and International Goat Genome Consortium. 2014. Design and characterization of a 52K SNP chip for goats. PLoS One 9:e86227. https://doi.org/10.1371/journal.pone.0086227.

Usman, T., Y. Yu, C. Liu, X. Wang, Q. Zhang, and Y. Wang. 2014 Genetic effects of single nucleotide polymorphisms in JAK2 and STAT5A genes on susceptibility of Chinese Holsteins to mastitis. Mol. Biol. Rep. 41:8293-8301. https://doi.org/10.1007/s11033-014 $-3730-4$. 